Секция 9. Углеродные и графеноподобные наноматериалы, дихалькогениды переходных металлов, перовскиты, органические полупроводники, молекулярные системы

\title{
Электромагнитный дрессинг наноструктур Кибис О.В.
}

Новосибирский государственный технический университет, 630073, Новосибирск, пр. К. Маркса, 20

DOI 10.34077/Semicond2019-366

Одним из активно развивающихся научных направлений в современной физике является исследование перенормировки (ренормализации) электронных свойств различных систем, обусловленной нерезонансным взаимодействием электронов с сильным высокочастотным электромагнитным полем. Поскольку частоты нерезонансного поля лежат далеко от характерных частот электронной системы, то это поле не поглощается электронами и, следуя общепринятой терминологии нелинейной оптики, называется «одевающим полем» (dressing field). Соответственно, ренормализация электронных свойств одевающим полем называется «электромагнитным одеванием» или «электромагнитным дрессингом» (electromagnetic dressing). Традиционно, электромагнитный дрессинг относится к юрисдикции нелинейной оптики и долгое время исследовался лишь применительно к атомарным и молекулярным системам в сильных лазерных полях. Однако успехи в технологии изготовления наноструктур привели к тому, что область приложения методологии электромагнитного дрессинга существенно расширилась: благодаря разнообразию наноструктур появилась возможность наблюдения новых фундаментальных эффектов на стыке нелинейной оптики и физики низкоразмерных электронных систем. Как следствие, в последние годы сформировался междисциплинарный тренд, основной задачей которого является исследование электромагнитного дрессинга различных наноструктур с учетом многообразия их электронных свойств. Проводя работы в рамках данного научного направления, мы теоретически исследовали электромагнитный дрессинг электронов в различных наноструктурах, включая квантовые кольца [1,2], дихалькогениды переходных металлов [3], графен [4,5] и спиновые транзисторы [6]. Из полученных нами результатов следует, что электромагнитный дрессинг существенным образом ренормализует стационарные электронные и спиновые характеристики наноструктур, приводя к появлению качественно новых светоиндуцированных явлений. В частности, одевающее поле индуцирует анизотропию электронных и спиновых свойств, приводит к появлению осциллирующей зависимости электронных транспортных характеристик как функции интенсивности одевающего поля, качественно меняет структуру уровней Ландау в магнитном поле и др. Предлагаемый доклад посвящен обсуждению этих новых физических эффектов.

Работа выполнена при частичной поддержке гранта РФФИ 17-02-00053.

[1] V. K. Kozin, I. V. Iorsh, O. V. Kibis, I. A. Shelykh, Physical Review B, 97, 155434 (2018).

[2] V. K. Kozin, I. V. Iorsh, O. V. Kibis, I. A. Shelykh, Physical Review B, 97, 155434 (2018).

[3] O. V. Kibis, K. Dini, I. V. Iorsh, I. A. Shelykh, Physical Review B, 95, 125401 (2017).

[4] I. V. Iorsh, K. Dini, O. V. Kibis, I. A. Shelykh, Physical Review B, 96, 155432 (2017).

[5] O. V. Kibis, S. Morina, K. Dini, I. A. Shelykh, Physical Review B, 93, 115420 (2016).

[6] A. S. Sheremet, O. V. Kibis, A. V. Kavokin, I. A. Shelykh, Physical Review B, 93, 165307 (2016). 